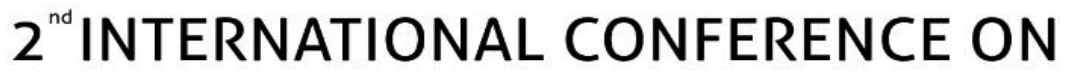 FUTURE OF TEACHING \& EDUCATION
}

Munich,Germany

6 - 8 December,2019

\section{The impact of professors' aptitudes, attitudes and professional development on teaching and learning: Case study at the University of Cuenca}

\author{
Vicente Guillermo Pacheco, Maria Isabel Espinoza, Sandra Cabrera Arias \\ University of Cuenca
}

\begin{abstract}
Continuous changes in social demand and development provide an acute and continuous pressure on universities. The question to be asked is whether higher education institutions in Ecuador possess the capacity to deliver graduates with the competences to provide timely economic, ecological and sustainable solutions for the problems society is increasingly confronted with. Additionally, higher education institutions should prepare graduates to find employment in a society characterized by greater uncertainty, extensive use of information technology, speed, risk, complexity and interdisciplinary work. To face this challenge, universities need professors to possess a mix of aptitudes, attitudes and professional development in teaching, research and services. Unfortunately, knowledge is sparse about the impact of the aptitude, attitude and professional development of the academic community on the readiness of their pupils to function effectively in a rapid changing and increasingly globalized environment. Accordingly, this paper assesses, using as case study the public University of Cuenca, the impact of professors' aptitudes, attitudes and professional development on teaching and students' learning. The study adopted an explanatory sequential mixed approach as research method for the collection, analysis and interpretation of the broad range of questions asked to professors and students. Understanding the likely implication of the variables, aptitude, attitude and professional development, on the quality of teaching and learning is fundamental for the design and carrying out of educational reforms. It is believed that results will facilitate the formulation of criteria for the correct definition of teaching quality, the promotion of professional training, and strengthening of academic performance.
\end{abstract}

Keywords: Higher education, aptitudes, attitudes, professional development, teaching and learning process 